\title{
Coexistence of degenerative aortic stenosis and wild type transthyretin-related cardiac amyloidosis: a potentially dangerous association that can be non-invasively identified
}

\author{
Simone Longhi ${ }^{1 *}$, Agnese Milandri ${ }^{1}$, Christian Gagliardi ${ }^{1}$, Massimiliano Lorenzini ${ }^{1}$, Francesco Saia ${ }^{1}$, Ornella Leone ${ }^{2}$,
} Pier Luigi Guidalotti ${ }^{3}$, Claudio Rapezzi ${ }^{1}$

From First European Congress on Hereditary ATTR amyloidosis

Paris, France. 2-3 November 2015

\section{Background}

Degenerative aortic stenosis (AS) and wild type transthyretin (TTR)-related cardiac amyloidosis (wt-ATTR) share a common demographic and clinical profile. It has been recently suggested that the coexistence of wt-ATTR could negatively influence the outcome of elderly patients with aortic stenosis undergoing transcatheter aortic valve replacement (TAVR). TTR-related cardiac amyloidosis can be accurately identified by technetium-99m-3, 3-diphosphono-1, 2 propanodicarboxylic acid (99mTc-DPD) scintigraphy. We decided to investigate the coexistence of cardiac amyloidosis in elderly patients with aortic stenosis referred for aortic valve replacement (TAVR or surgery).

\section{Methods}

Since October 2014 we prospectively evaluated with 99mTc-DPD scintigraphy all patients diagnosed with degenerative AS and one or more of the following: paradoxical low flow-low gradient severe AS, QRS voltage-left ventricular (LV) wall thickness mismatch, echocardiographic findings suggestive of myocardial infiltrative disease (increased thickness of atrio-ventricular valves or interatrial septum or right ventricular free wall, pericardial effusion, granular sparkling of ventricular myocardium). Cases with intense myocardial tracer uptake underwent endomyocardial biopsy (EMB).

'Department of Experimental, Diagnostic and Specialty Medicine - DIMES, Alma Mater Studiorum, University of Bologna, Cardiology, 40138, Bologna, Italy

Full list of author information is available at the end of the article

\section{Results}

Five out of 42 patients underwent $99 \mathrm{mTc}$-DPD scintigraphy that showed strong myocardial uptake in all. EMB demonstrated TTR-related amyloid infiltration in all cases. Genetic analysis excluded TTR gene mutations; so wt-ATTR was diagnosed. Median age was 88 (range 86-91), 3/5 were males. Two had a history of carpal tunnel syndrome and all were symptomatic for exertional dyspnoea (NYHA class III-IV). At echocardiography mean LV wall thickness was $18 \pm 2 \mathrm{~mm}$, LV ejection fraction was $54 \pm 10 \%$ (38\%-64\%). Functional aortic valve area was between 0.4 and $0.9 \mathrm{~cm} 2$; one case had a low flowlow gradient and reduced LV ejection fraction (38\%); maximum aortic gradient in the other 4 cases was $59 \pm 30 \mathrm{mmHg}$. Atrio-ventricular valve thickening was present in all, and mild pericardial effusion was present in 3 cases. Tissue Doppler $\mathrm{S}$ wave was reduced in all cases. QRS voltage was normal in one and increased in 4 patients.

\section{Conclusion}

Coexistence of degenerative AS and wt-ATTR cardiac amyloidosis (a potentially dangerous condition in patients undergoing AVR or TAVR) can be suspected by clinical and echocardiographic elements and effectively diagnosed by $99 \mathrm{mTc}-\mathrm{DPD}$ scintigraphy.

\footnotetext{
Authors' details

'Department of Experimental, Diagnostic and Specialty Medicine - DIMES, Alma Mater Studiorum, University of Bologna, Cardiology, 40138, Bologna, Italy. ${ }^{2}$ Department of Pathology, Sant'Orsola-Malpighi Hospital, Pathology, 40138, Bologna, Italy. ${ }^{3}$ Department of Experimental, Diagnostic and Specialty
} 
Published: 2 November 2015

doi:10.1186/1750-1172-10-S1-P45

Cite this article as: Longhi et al:: Coexistence of degenerative aortic stenosis and wild type transthyretin-related cardiac amyloidosis: a potentially dangerous association that can be non-invasively identified. Orphanet Journal of Rare Diseases 2015 10(Suppl 1):P45.

Submit your next manuscript to BioMed Central and take full advantage of:

- Convenient online submission

- Thorough peer review

- No space constraints or color figure charges

- Immediate publication on acceptance

- Inclusion in PubMed, CAS, Scopus and Google Scholar

- Research which is freely available for redistribution

Submit your manuscript at www.biomedcentral.com/submit
Ciomed Central 